\title{
Reforma agraria y movilización campesina en Chile (1967-1973) y Perú (1969-1976)
}

\author{
Octavio Avendaño \\ Universidad Alberto Hurtado, Santiago, Chile \\ Universidad de Chile, Santiago, Chile \\ Email: oavendan@gmail.com
}

\begin{abstract}
Resumen $^{1}$ : Este artículo compara dos experiencias de reforma agraria que se dieron en Chile, en el período 1967-1973, y en Perú, entre 1969 y 1976. En ambas se impulsó la creación de nuevas formas de propiedad colectiva y una amplia participación campesina. Además, la reforma agraria provocó la modificación del sistema de tenencia, alteró la estructura de poder y benefició a una parte importante de la población rural. Sin embargo, mientras en Chile la reforma fue promovida en un contexto democrático, en Perú fue impulsada bajo un régimen autoritario controlado por los militares. En base al método de la diferencia y la semejanza, se reconocen aquellos fenómenos comunes que permiten entender por qué motivos tanto en Chile como en Perú las reformas agrarias alcanzaron resultados similares.
\end{abstract}

Palabras clave: Reforma agraria, movimiento campesino, Chile, Perú

\section{Agrarian reform and peasant mobilization in Chile (1967-1973) and Peru (1969-1976)}

\begin{abstract}
This article compares two experiences of agrarian reforms that took place in Chile in the period 1967-1973 and in Peru between 1969 and 1976. In both, the creation of new forms of collective ownership and broad peasant participation were promoted. In addition, agrarian reform led to a change in the tenure system, altered the power structure and benefited to a significant portion of the rural population. However, while in Chile the reform was promoted in a democratic context, in Peru it was promoted under an authoritarian regime controlled by the military forces. Based on the method of difference and similarity, we identify the common phenomena that allow us to understand the reasons why, in both Chile and Peru, agrarian reforms obtained similar results.
\end{abstract}

Keywords: Agrarian reform, peasant movement, Chile, Perú

\section{Reforma agrária e mobilização camponesa no Chile (1967-1973) e no Peru (1969-1976)}

Resumo: Este artigo compara duas experiências de reforma agrária que ocorreu no Chile, no período 1967-1973, e no Peru, entre 1969 e 1976. Em tanto a criação de novasformas de propriedade coletiva e ampla participação camponês foi incentivado. Além disso, a reforma agrária le vou à modificação do sistema de posse, altero ua estrutura de poder e beneficiou uma parte importante da população rural. 
Reforma No entanto, en quanto no Chile foi promovido em um contexto democrático no Peru foi conduzido sob controlada pelo regime autoritário militar. Com base no método da diferença e semelhança, esses fenômenos comuns que nos permitam compreender sobre as reformas agrárias que razãotanto no Chile e Peru são reconhecidos obtiveram resultados semelhantes.

Palavras-chave: reforma agrária, movimento camponês, Chile, Peru

$* * *$

\section{Introducción}

Desde las primeras décadas del siglo XX,varios han sido los procesos de reforma agraria que se han venido implementando en países de América Latina y el Caribe. Por lo general estas reformas se han centrado en una política de distribución de tierras con miras a integrar o mejorar la condición de vida de la población campesina. Como parte de las reformas también se consideran las políticas de colonización y ocupación de terrenos fiscales que han sido promovidas por determinados gobiernos (García, 1967; McCoy, 1969; Lapp, 2004; Albertus, 2004). Desde mediados de los años sesenta se vienen presentando una serie de tipificaciones de la reforma agraria destinadas a caracterizar su modo de implementación y el grado de modificación de la estructura de propiedad prevaleciente en la fase previa.

Tres tipos de reforma agraria tendieron a ser reconocidos por los principales estudiosos en los años sesenta y setenta (Gunder Frank, 1965, p. 184.; McCoy, 1969; Mattelart, 1972, p. 72). El primer tipo de reforma agraria puso el acento en la tecnificación de las labores productivas sin que se intentara modificar el sistema de tenencia de la tierra y el predominio de la gran propiedad hacendal. Normalmente se trató de reformas impulsadas por los sectores conservadores y quienes controlaban la gran propiedad, como ocurrió en Venezuela y Colombia a inicios de los años sesenta (Chonchol, 1994, p.279-288). El segundo intentó llevar a cabo un proceso de integración del campesinado por medio de la expropiación de las haciendas improductivas y la distribución de nuevas unidades de producción agropecuaria, normalmente pequeñas y medianas. Las reformas agrarias en México bajo Cárdenas (1934-1940), en Guatemala con Jacobo Arbens (1952-1954) y en Chile bajo los gobiernos de Frei Montalva (1964-1970) y Allende (19701973), se ubicarían dentro de ese segundo tipo. El tercer tipo de reforma se registró en el contexto de procesos revolucionarios, que intentaron una transformación acelerada y radical del orden existente. Esto incluye transformar las estructuras sociales, en general, y por ende la eliminación de la gran propiedad. E incluye la modificación de la orientación del Estado. Bajo ese tipo de reformas los terratenientes resultaron derrotados y desplazados del poder (Kay y Pineda, 1998, p. 76). Un claro ejemplo de este tercer tipo de reforma agraria sería la cubana iniciada en 1959 y antes la boliviana en el contexto de la revolución de 1952. 
A esta tipología, en años más recientes, el trabajo de Michael Albertus (2015) agrega la presencia de regímenes autocráticos en los cuales se habrían expropiado los latifundios y efectuado la subdivisión en pequeñas y medianas propiedades, junto a la creación cooperativas u otras empresas agrícolas basadas en el trabajo colectivo. Dentro de este último grupo destacaría la reforma agraria llevada a cabo por el general Juan Velasco Alvarado en Perú, entre 1969 y 1976.

El propósito de este artículo es comparar la reforma agraria iniciada en Chile a partir de 1967, una vez que fueron aprobadas por el Congreso Nacional las leyes de Sindicalización Campesina (16.625) y Reforma Agraria (16.640), entre abril y junio de 1967con la aplicada por el general Velasco Alvarado en Perú, en el período comprendido entre 1969 y 1976. Ambas experiencias se caracterizaron por llevar a cabo un efectivo proceso de expropiación de las grandes propiedades -en especial las improductivas en el caso chileno-, se incentivó la participación y organización de los campesinos, se asumió el control estatal de las aguas y otras medidas de fomento productivo agrícola. Adicionalmente, los dos procesos de reforma agraria transformaron la estructura de poder y de propiedad, sin que ella fuera reestablecida en las épocas sucesivas, ni en Chile (Kurtz, 2004; Gómez, 2015, p. 143) ni tampoco en el Perú (Chonchol, 1994, p. 310). Es por eso que, en importancia y nivel de transformación, las reformas agrarias chilena y peruana se ubican después de los casos emblemáticos de México, Bolivia y Cuba.

En cuanto al caso chileno, habría que señalar que se trata de una reforma agraria aplicada bajo una creciente democratización política, que coincide con los gobiernos de Eduardo Frei (1964-1970) y Salvador Allende (1970-1973), lo que facilita su avance y nivel de profundización. La legislación aprobada en 1967 reconoció y tomó como base aspectos institucionales aprobados por el gobierno de Jorge Alessandri, en 1962 y 1963, en el cual se aprueba la primera legislación sobre el tema y la reforma constitucional que facilita las expropiaciones. En cuanto al caso peruano, el gobierno de Velasco Alvarado se establece tras derrocar al presidente Belaúnde Terry, en 1968. En tal sentido, la reforma agraria peruana que se pone en marcha en 1969 se realiza en condiciones institucionales disímiles, y bajo un régimen político completamente distinto. En otras palabras, existen similitudes entre el caso chileno y el peruano, así como también similitudes importantes respecto a ciertos aspectos de la implementación pero sobre todo en los resultados alcanzados. Sin embargo, habría diferencias importantes en cuanto al contexto político bajo el cual se llevan a cabo ambas reformas. Asimismo, en Perú se dio un activo movimiento campesino desde antes del inicio de la reforma agraria, mientras que en Chile el campesinado se organiza, y se constituye en movimiento, desde el momento en que el gobierno de Frei (1964-1970) decide hacer efectiva la reforma agraria.

Mediante el uso del método de la diferencia y la semejanza, se busca en este artículo efectuar un reconocimiento de los aspectos comunes que permitan entender por qué razón casos distintos desde el punto de vista del 
sistema político logran resultados similares. En tal sentido, y atendiendo lo que plantea la literatura especializada (Ragin, 1989; Morlino, 2005; PérezLiñán, 2015), al efectuar una comparación de tipo binaria, o con un reducido número de casos, las diferencias no permiten explicar por qué se pueden alcanzar resultados similares. En cambio, las similitudes facilitan el reconocimiento de aquellos factores, o situaciones comunes, que estarían incidiendo en el resultado del proceso de reforma agraria.

\section{Panorama previo a la reforma agraria}

A inicios de los años sesenta, en varios países de la región, es posible advertir una suerte de consenso en amplios sectores respecto a la necesidad de impulsar procesos de reforma agraria. En parte, dicho consenso fue consecuencia de la recepción que tuvo la política de Alianza para el Progreso, impulsada por el presidente Kennedy en el marco de la conferencia celebrada en Punta del Este, en 1961. Pero también fue el resultado de una serie de diagnósticos que surgieron al interior de ciertos países, acompañados de estudios promovidos por la Comisión Económica para América Latina (CEPAL). Con posterioridad se amplió la red de organismos internacionales que colaboraron con los gobiernos que se decidieron modernizar las estructuras productivas, o llevar a cabo una política de redistribución territorial, sobresaliendo la labor de FAO, ICIRA y el PNUD. En el contexto de los años sesenta, la reforma agraria no sólo fue concebida como una medida preventiva, para evitar la propagación de focos de guerrilla en las zonas rurales, sino más bien como una solución a los problemas del desarrollo, el déficit alimentario y las inequidades de la población rural, condicionados por la vigencia del latifundio y de la gran propiedad en general.

En años anteriores a la política de la Alianza para el Progreso, en Chile y en Perú se venían llevando a cabo una serie de procesos internos que apuntaban y justificaban la necesidad de la reforma agraria. En Chile, por un lado, ya existían propuestas de reforma de parte de los partidos de izquierda, Comunista (PC) y Socialista (PS), así como también de sectores socialcristianos vinculados a la Falange y luego, desde 1957, a la Democracia Cristiana (DC). Hacia fines de los años cincuenta las propuestas de reforma agraria se orientaban, principalmente, a la expropiación de los latifundios improductivos, integrar a la población campesina y ampliar el mercado interno, con miras a profundizar el desarrollo de la actividad industrial (Cf. Huerta, 1989; Avendaño, 2016, 2017). Esta concepción acerca del propósito que debía tener la reforma agraria fue complementada posteriormente con planteamientos mucho más radicales que surgieron, en gran medida, como consecuencia del carácter adoptado por el proceso político desde mediados de los años sesenta. En Perú, por su parte, el diagnóstico inicial apuntaba a tener que abordar la compleja y diferenciada estructura agraria que se había ido configurando desde hacía varias décadas (Matos Mar, 1976; Seligmann, 1995). Se destacaba la importancia que tenía el complejo azucarero y algodonero de la costa, así como la presencia de trabajadores asalariados. Adicionalmente se hacía hincapié en el predominio de las gran- 
des haciendas ubicadas en la sierra, en las que persistían relaciones serviles y semiserviles, así como en la realidad de las comunidades indígenas ubicadas en la selva y en las zonas cordilleranas. Por otra parte, en Perú se venía desencadenando un importante movimiento campesino, que desde 1956 se expresó en el aumento de las huelgas y del número de sindicatos, sobre todo en la costa. A juicio de Valderrama (1985, p. 136), el aumento de los conflictos en las zonas rurales, unido a la aparición de focos de guerrilla, en 1962, contribuyeron a resquebrajar el orden oligárquico antes de que los militares llegaran al poder, en 1968.

En la fase previa a la implementación de las reformas en ambos países, la agricultura venía presentando situaciones deficitarias sin lograr cubrir la demanda de alimentos que existía en los centros urbanos. Con excepción de los complejos modernizados ubicados en la costa, el agro peruano estaba prácticamente estancado a inicios de los años sesenta (Chonchol, 1994, p. 303). En las áreas más tradicionales, desde el punto de vista productivo, la incapacidad que presentaba el agro para absorber mano de obra, generaba altas tasas de desocupación. Matos Mar (1984, p. 31) llega a sostener que fue precisamente la decadencia del agro la que le restó poder a los terratenientes, quienes comenzaron a perder influencia política y demostrar incapacidad para defender sus propios intereses. En Chile, por su parte, en el lapso del período comprendido entre 1955 y 1965 se redujo de manera considerable el número de trabajadores en las haciendas de más de 200 hectáreas, pasando de 266.000 a 230.000 personas (Kay, 1986, p. 44). La disminución fue consecuencia de la subutilización del suelo agrícola y, al mismo tiempo, de la introducción de tecnología en las faenas productivas en las haciendas más modernizadas.

Uno de los aspectos que más se enfatizaba en los años previos a la reforma agraria era el problema de la concentración de la propiedad, y la presencia de unidades subfamiliares, conocidas como minifundios, que no lograban proporcionar los elementos necesarios para la sobrevivencia de quienes explotaban ese tipo de predios. De acuerdo a lo que se observa en al siguiente tabla, las propiedades familiares y subfamiliares correspondían a los pequeños productores de origen campesino. El productor familiar, disponía de su propio trabajo y de los miembros de la familia para poder subsistir. En cambio, el minifundista subfamiliar no lograba generar un nivel de producción para mantener a su familia, para asegurar su propia subsistencia. Frente a ello debía combinar sus labores como pequeño productor con las de trabajador asalariado ocasional en las grandes haciendas. Los grandes propietarios eran, por el contrario, un sector bastante heterogéneo, en particular si se considera el tamaño de su propiedad, la que por lo general superaba las 80 y las 100 hectáreas, o más, si la zona se encontraba muy degradada desde el punto de vista agroecológico.

Las cifras sobre tenencia de la tierra, para la primera mitad de los años sesenta, reflejan con claridad el problema de la concentración de la propiedad agrícola en ambos países. En ese entonces, en Chile el 37\% de las propiedades minifundistas controlaban tan sólo el 0,3\% de la superficie de 
uso agrícola. Por el contrario, las grandes propiedades representan el 6,9\% del total de los predios, ocupando el $81,2 \%$ de la superficie territorial. En Perú, el 84,4\% de los productores eran minifundistas, quienes tan solo controlaban el 6,1\% de las superficies; en cambio, la grandes propiedades eran el 1,2\% del total de unidades productivas, pero lograban ocupar el 75,2\% de la tierra.

\section{Tabla 1 \\ Predios y superficies agrícolas en Chile y Perú, primera mitad de la década de 1960}

\begin{tabular}{|l|c|c|c|c|c|c|c|c|}
\hline \multirow{2}{*}{ Tipos de predio } & \multicolumn{9}{|c|}{ Chile } & \multicolumn{5}{c|}{ Perú } \\
\cline { 2 - 9 } & Número & $\%$ & $\begin{array}{c}\text { Superficies } \\
\text { (en hectáreas) }\end{array}$ & $\%$ & Número & $\%$ & $\begin{array}{c}\text { Superficies } \\
\text { (en hectáreas) }\end{array}$ & $\%$ \\
\hline Comunidades (*) & --- & --- & -- & -- & 808 & 0,1 & 1.604 .000 & 8,6 \\
Subfamiliar & 55.800 & 37,0 & 78.100 & 0,3 & 719.110 & 84,4 & 1.124 .000 & 6,1 \\
Familiar & 60.400 & 40,0 & 1.966 .200 & 7,1 & 98.370 & 11,6 & 876.000 & 4,7 \\
Mediano & 24.400 & 16,1 & 3.149 .900 & 11,4 & 23.250 & 2,7 & 1.006 .000 & 5,4 \\
Grande & 10.400 & 6,9 & 22.518 .100 & 81,2 & 10.462 & 1,2 & 13.995 .000 & 75,2 \\
& & & & & & & & \\
Total & 151.100 & 100 & 27.712 .300 & 100 & 852.000 & 100 & 18.605 .000 & 100 \\
\hline (*) Se refiere a comunidades indigenas.
\end{tabular}

Fuente: Elaboración propia en base a datos del Censo Agrícola (Chile) de 1955. Cf (Gómez, 1986, p. 7); Barraclough y Collarte (1972, p. 398).

En la misma línea, otros estudios demostraron que hacia 1965, las propiedades menores a 10 hectáreas, constituían el 61,8\% del total de predios, ocupando sólo el 1,4\% de la superficie territorial (Huerta, 1989, p. 211). Analizado en términos de hectáreas de riego básico (HRB), los predios menores a 10 constituían el $81 \%$ en tan solo 9,7\% del total de ese tipo de superficie; en cambio, las explotaciones mayores a $80 \mathrm{HRB}$, que no sobrepasaban el 2,0\% de los predios, ocupaban el 55,3\% de esas tierras (Cereceda y Dahse, 1980, p. 14). Por su parte, en lo que respecta al caso peruano, los datos del Comité Interamericano de Desarrollo Agrícola (CIDA),pusieron también en evidencia el fenómeno de la concentración de la propiedad, en desmedro de las pequeñas unidades minifundistas. Según datos proporcionados por ese organismo, en Perú el 83,2\% de las unidades productivas agrícolas poseía menos de 5 hectáreas, las que se distribuían en el 5,5\% del total de la superficie territorial disponible en todo el país. Por el contrario, las propiedades superiores a las mil hectáreas constituían el 1\%, ocupando el 69,7\% de la tierra (Barraclough y Collarte, 1972, p. 396). Tomando en cuenta estos antecedentes acerca de la tenencia de la tierra, se procedió, tanto en Chile como en Perú,a llevar a cabo una reforma agraria efectiva. 


\section{Una comparación binaria entre las reformas agrarias de Chile y Perú}

Como se ha podido apreciar existe un diagnóstico más o menos similar en el momento en que se aplica la reforma agraria en Chile y en Perú. Ese diagnóstico daba cuenta de un problema en la tenencia de tierras, debido a la concentración en la gran propiedad, y una situación deficitaria respecto a la producción de alimentos y abastecimiento al mercado interno. En ambos países se intentan aplicar reformas agrarias, en los años previos a la aprobación de la Ley 16.640, de junio de 1967, en el caso de Chile, y a la llegada de los militares al poder en Perú, en 1968. Sin embargo, en el momento de su aplicación más efectiva, la reforma agraria se da bajo condiciones institucionales completamente distintas en Chile respecto a Perú. En efecto, mientras en Chile, la reforma agraria se lleva cabo en el contexto de un gobierno democrático y, al mismo tiempo, de creciente democratización, en Perú, en cambio, se materializa, de manera efectiva, tras el derrocamiento del presidente Belaúnde Terry por la "revolución militar" liderada por el general Velasco Alvarado.

Otra diferencia importante entre ambos casos dice relación con el protagonismo del movimiento campesino antes de iniciada la reforma agraria. En Chile, la participación campesina y la capacidad organizativa fueron bajas debido a una serie de impedimentos legales y presiones efectuadas por los grandes terratenientes,a los gobiernos que se sucedieron desde fines de la década de 1930 (Affonsoet al, 1970; Loveman, 1976; Bruna, 1985).Así, la reforma agraria y la sindicalización campesina se transformaron en las principales banderas de lucha de una parte de la izquierda chilena, representada por el PC. Durante el gobierno de Gabriel González Videla (1946-1958) fue aprobada La Ley 8.811, de Sindicalización Campesina, que limitó considerablemente la posibilidad de organización de los trabajadores agrícolas, dificultando además el derecho a huelga.

Esta legislación se mantuvo vigente hasta el año 1967. Por veinte años, los conflictos y la organización campesina en las zonas rurales disminuyeron de manera considerable, con la excepción de los esfuerzos desplegados por asociaciones vinculadas a la Iglesia Católica y, no obstante encontrarse enla clandestinidad, por los agitadores pertenecientes al PC (Loveman, 1976). Uno de los primeros compromisos asumidos por Eduardo Frei Montalva (1964-1970) al iniciar su gobierno fue enviar una nueva legislación sindical para los campesinos, acompañada del proyecto de reforma agraria. Ambos proyectos fueron aprobados por el Congreso Nacional durante el primer semestre de 1967. Previo a la aprobación de la Ley 16.625 de Sindicalización Campesina, en abril de 1967, el gobierno se esmeró por impulsar la sindicalización aprovechando el vínculo que existía entre el PDC y determinadas organizaciones campesinas. Más importante aún, resultó ser la labor emprendida por el INDAP de formar y asesorar a dirigentes campesinos. La labor de asesoría de los funcionarios del INDAP tendió a transformarse muchas veces en relación de dependencia, combinada con 
asistencialismo (Affonso et al, 1970, p. 251). Solo en 1965, INDAP logró constituir 488 organizaciones sindicales, con alrededor de 20 mil socios, y a inicios de 1967, antes de aprobada la nueva legislación, promovió la formación de 106 sindicatos comunales.

Una tendencia contraria se registra en Perú desde los inicios del siglo XX, época en la cual se registraron una serie de insurrecciones campesinas e indígenas. Desde la década de 1920 el APRA y el Partido Comunista Peruano (PCP), llevaron a cabo una serie de acciones orientadas a conducir a los trabajadores asalariados del complejo azucarero y algodonero de la costa, donde predominaban las relaciones salariales. Se trató de un movimiento que no dependió del Estado, sino más bien, como ocurre con los sindicatos de trabajadores de la costa, con una estrecha relación con los partidos. Pero el mayor protagonismo adquirido por el movimiento campesino, se produjo a raíz de las luchas ocurridas entre 1956 y 1964 (Valderrama, 1985, p. 136). La mayoría de ellas se expresaron a través de huelgas y movilizaciones que fueron socavando, aunque de manera gradual, el orden oligárquico en el Perú. Por otra parte, desde inicios de los años sesenta, y como consecuencia del impacto que genera la revolución cubana en el resto del continente, se desarrolla en Perú un importante movimiento guerrillero en las zonas rurales (Rubio, 2013, p. 221). Las vanguardias guerrilleras pretendieron conducir la ola de protesta desplegada por los sindicatos y las organizaciones campesinas, pues consideraban que ellas constituían una forma de lucha reivindicativa, sin contemplar la transformación radical de la sociedad, ni mucho menos la toma del poder. Aun así, el movimiento guerrillero desencadenado a partir de 1965, junto al fracaso del programa de reformas impulsado por el gobierno de Balaúnde, se tradujo en una de las motivaciones más importantes para la intervención y el carácter radical, que tuvieron las transformaciones efectuadas por el "gobierno revolucionario" de las Fuerzas Armadas, iniciado el 3 de octubre de 1968.

La reforma agraria peruana tuvo un carácter marcadamente antioligárquico, porque además de la eliminación del latifundio estuvo acompañada de una serie de otras medidas que los militares adoptaron para debilitar a ese sector. Adicionalmente, la reforma agraria tuvo otro objetivo que fue más allá de lo económico-productivo. A diferencia de lo que ocurre en Chile, los militares peruanos liderados por el general Juan Velasco Alvarado consideraban la reforma agraria como un requisito "indispensable para asegurar la defensa nacional” (Pease y Romero, 2013, p. 241). Consideraban, a su vez, que el territorio poseía una significativa presencia de población indígena, asentada en comunidades, que no se sentía parte de la nación peruana. Complementando esa misma idea, se podría agregar que, al igual que durante la revolución boliviana de 1952, con la reforma agraria, y las otras medidas de corte antioligárquicas, los militares también pretendían contribuir a la unidad nacional.

Pese a estas diferencias, también se observan similitudes importantes. En ambos casos, la reforma agraria efectiva estuvo precedida de inten- 
tos y antecedentes previos. En el caso chileno, fue fundamental la aprobación de la primera Ley de Reforma Agraria, bajo el gobierno de Jorge Alessandri, en 1962. Esta legislación permitió establecer los organismos a través de los cuales se va a conducir, posteriormente, todo el proceso de expropiaciones, de organización del sector reformado, y de fomento a la sindicalización campesina. Esa fue la labor que asumieron la Corporación de la Reforma Agraria (CORA) y el Instituto de Desarrollo Agropecuario (INDAP). En 1963, encontrándose todavía Alessandri en el gobierno, el Ejecutivo logró la aprobación del proyecto de reforma constitucional que facilitó las expropiaciones, al introducir la modalidad de pago en diferido por parte del Estado. También fueron cruciales aquellas leyes decretadas al inicio del gobierno de Frei Montalva, mientras se discutía el proyecto de reforma agraria, destinadas a evitar la subdivisión por parte de los terratenientes, como mecanismo para evitar la reforma agraria (Avendaño, 2016). En Perú, desde inicios de los años sesenta, hubo dos intentos de reforma agraria. El primero, asumido por los militares, en 1962, con la finalidad de frenar el movimiento insurgente encabezado por Hugo Blanco en los valles de la Convención y Lares, ubicados en la zona de Cuzco. Sin embargo, esta reforma se limitó solo a esa zona, sin que se extendiera hacia el resto del país (Chonchol, 1994, p. 304; Fajardo, 2009, p. 217). El segundo intento se produjo durante el gobierno del presidente Belaúnde Terry, en 1964. Para ello se dictó una ley que planteaba la redistribución de tierra. La mencionada legislación tuvo una serie de limitaciones, siendo la más importante el hecho de excluir de las expropiaciones a los grandes complejos azucareros, así como a muchos de los latifundios más deficitarios desde el punto de vista productivo. La aplicación de esta reforma generó una fuerte reacción de parte de los terratenientes, lo que unido a las lentitudes y complejidades generadas en el proceso de expropiaciones, benefició a un porcentaje inferior al 5\% de la población campesina.

Desde luego, las principales similitudes han sido evidenciadas en los resultados del proceso de reforma agraria. En relación al nivel de profundidad, en el número de superficies expropiadas, y de población beneficiada, tanto la reforma agraria chilena como la peruana fueron las dos más importantes de las realizadas a lo largo del período que se inaugura a inicios de los años sesenta. En ambos casos, además, la reforma agraria estuvo acompañada de otro tipo de iniciativas destinadas a promover la organización, la formación de dirigentes y la instrucción del campesinado. ¿Qué explica entonces que, a pesar de las diferencias, los resultados entre ambos casos sean similares? Para responder a esta pregunta es necesario identificar las similitudes que se dan en el período de aplicación. En particular, aquellas que tienen que ver con los procedimientos y el modo en que se vinculan los campesinos con el Estado. Son esas similitudes las que permitirían explicar la coincidencia en los resultados de la aplicación de la reforma agraria en Chile y en Perú. 


\section{Reforma agraria chilena}

Como se ha mostrado de manera más detallada en otro trabajo (Avendaño, 2017), la reforma agraria chilena comienza a partir de 1962, y es el resultado de un proceso de transformación gradual a nivel de las instituciones políticas, como de aquellas encargadas de la distribución de la tierra y la organización campesina. Se pudo avanzar en la aprobación y la profundización de la reforma agraria, debido a los cambios institucionales y políticos que se registraron a partir de la coyuntura de 1958, y sobre todo la aprobación de reformas electorales alcanzadas durante ese año (Lapp, 2004). La más importante de las reformas fue la aprobación de la "cédula única” en los procesos electorales, con lo cualse puso término al cohecho que ejercían los terratenientes y los partidos de la derecha. Otro aspecto relevante fue la derogación de la Ley de Defensa Permanente de la Democracia, que había excluido al PC y restringido aún más las posibilidades de promover organizaciones campesinas en las zonas rurales.

Las reformas, en especial el establecimiento de la "cédula única”, permitieron un crecimiento de aquellas fuerzas políticas que promovían la reforma agraria. En un sentido contrario, los partidos de derecha se vieron afectados en las elecciones que se sucedieron entre 1961 y 1965. Por otra parte, se produjo, a partir de ese año, una mayor cooperación entre socialistas y comunistas, expresada en el impulso para la creación de federaciones y una confederación campesina dirigida por miembros de esos partidos. En paralelo, el PDC fue experimentando un crecimiento significativo desde el punto de vista electoral, hasta su triunfo en las elecciones de 1964. Alessandri, en los primeros años de su gobierno, se vio en la necesidad de ceder a la presión que en ese entonces comenzaron a ejercer la Iglesia, a parte de la que venían ejerciendo la izquierda y el PDC (Kaufman, 1972). A las presiones internas se sumó la propuesta formulada en el marco de la Alianza para el Progreso, lo que llevó al gobierno de Alessandri a ceder por medio de una reforma agraria cuyo efecto resultó ser bastante tenue, al punto de ser bautizada con el nombre de "reforma de macetero".

\section{De política de colonización a distribución territorial}

En Chile, la reforma agraria estuvo antecedida por una política de colonización, que desde la década de 1920, el Estado fomentó en terrenos fiscales ubicados en aquellas zonas consideradas apartadas. Con la aprobación de la Ley 15.020 de Reforma Agraria, bajo el gobierno de Alessandri, en 1962, ala antigua Caja de Colonización Agrícola pasó a ser la Corporación de la Reforma Agraria (CORA), junto a la creación del Instituto de Desarrollo Agropecuario (INDAP) y el Tribunal de Expropiaciones Agrarias. El gobierno de Alessandri se limitó, principalmente, a la compra de terrenos fiscales y a la asignación territorial a familias que no necesariamente eran de origen campesino. Durante su gobierno, no se hicieron efectivas las expropiaciones a particulares. 
Cuando se da inicio al gobierno de Frei Montalva fue necesario acudir a la legislación aprobada por el gobierno de Alessandri, mientras que el proyecto enviado por el Ejecutivo se discutía en el Congreso Nacional. El trámite legislativo del proyecto de reforma agraria, así como el de sindicalización campesina, tomó más de dos años. Mientras tanto, el gobierno de Frei hizo uso de las instituciones creadas en la administración de Alessandri, CORA e INDAP, aumentando los recursos y el número de personal en cada una de ellas (Moreno, 2013). Para llevar a cabo expropiaciones, se basó en la Ley 15.020 y en las posibilidades que ahora ofrecía la reforma introducida al artículo 10 de la Constitución de 1925, al establecer el pago en diferido por un plazo de quince años máximo. En el intertanto, se produjo en diversas provincias de la zona central un proceso de subdivisiones, mediante ventas ficticias por parte de los terratenientes, pensando en evitar las expropiaciones, una vez que fuera aprobada la nueva Ley de Reforma Agraria enviada por el gobierno (Gómez, 1986, pp. 12-13). Ante tal situación, el gobierno tuvo que enviar, de manera rápida, un proyecto de ley que fue aprobado en abril de 1966 (Ley 16.465). De acuerdo a esta normativa, ningún predio mayor a 80 HRB podía ser subdividido sin la autorización previa de parte de la CORA.

Desde el momento en que el gobierno de Frei decide poner en marcha la reforma agraria, se define, para la organización del sector reformado, establecer el sistema de asentamientos (Echenique, 1972, p. 104; Cereceda y Dahse, 1980, p. 47; Huerta, 1989, p. 247). Los asentamientos fueron concebidos como formas de propiedad de carácter colectiva, que operaban de esa forma de manera transitoria. Luego de cinco años los campesinos beneficiados, integrantes de un asentamiento, podían decidir si seguían operando de esa forma, o bien si optaban por la parcelación y asignación individual de predios. Desde luego, en el período comprendido entre el inicio del gobierno de Frei y la aprobación de la Ley 16.640, en junio de 1967, el ritmo de las expropiaciones fue bastante lento. Al interior del Congreso Nacional se dio un intenso debate, tanto de parte de quienes promovían la aprobación del proyecto, como por parte de sus detractores. En el marco de ese debate se fue imponiendo una interpretación de las teorías del derecho natural, promovida principalmente por un sector del PDC, que se traduciría en el principal fundamento jurídico para justificar las expropiaciones y la redistribución de la propiedad, entre los trabajadores agrícolas y campesinos carentes de tierra. En el fondo, con ello se le daba un fundamento doctrinario y jurídico a la consigna "la tierra para el que la trabaja", que la izquierda había comenzado a difundir desde fines de los años de la década de 1930 .

La reforma agraria fue planteada como una política de distribución territorial, orientada a integrar y organizar el campesinado. Incluso se aspiraba a la formación de un segmento de productores agrícolas, con capacidad productiva, a fin de contrarrestar las inequidades que existían entre la población rural. En términos estrictamente económicos, con la reforma se pretendía una mayor racionalización y un aumento de la producción agrícola, con el fin de revertir el déficit que venía registrando la agricultura para la 
generación de bienes alimenticios. Subyacente al espíritu de la reforma, existía una pretensión de debilitar a los sectores tradicionales, lo que se hizo más explícito en los años de profundización de la reforma agraria, durante el gobierno de la Unidad Popular (1970-1973).

\section{Reforma agraria efectiva, 1967-1973}

En estricto rigor, con la aprobación de la Ley 16.640 se hace efectiva la reforma agraria centrada en la expropiación de grandes predios, mal trabajados y explotados, para ser distribuidos entre la población campesina y los trabajadores agrícolas en general. El proyecto enviado por el gobierno, para ser discutido y tramitado al interior del Congreso Nacional, planteaba explícitamente la necesidad de terminar con el latifundio, el cual se debía reemplazar por formas de propiedad campesina, individuales o en cooperativas. Además, el proyecto hacía hincapié en la necesidad de promover el desarrollo cultural junto a la participación del campesinado. Antes de que se aprobara la nueva Ley de Reforma Agraria, el gobierno logró el apoyo que necesitaba en la Cámara de Diputados y en el Senado para modificar el artículo 10 de la Constitución de 1925, que garantizaba el derecho de propiedad.

La Ley 16.640 establecía que debían ser expropiados los predios mayores a $80 \mathrm{HRB}$, que estuvieran mal trabajados, explotados de manera deficiente o simplemente abandonados. Se excluía de la expropiación a las grandes propiedades ubicadas en el secano costero, o en zonas precordilleranas, así como también a las empresas agroindustriales y aquellos predios que mostraran un importante nivel de producción, como ocurría en el caso de las viñas. Los propietarios de los predios expropiados tenían derecho a escoger una reserva, inferior a las $80 \mathrm{HRB}$, que normalmente eran las mejores tierras del predio. De la expropiación del predio se procedía a la organización de los asentamientos, que como ya se dijo consistían en formas de propiedad colectiva de carácter transitorio, dado que en un plazo de cinco años ofrecían la posibilidad, a los campesinos beneficiarios, de optar por una propiedad familiar o seguir manteniendo la misma modalidad.

Junto con las expropiaciones y la formación de los asentamientos, la Ley 16.640 definió a las aguas como bien de uso público. De ese modo, se modificaba la normativa vigente desde la aprobación del Código de Aguas, en 1951, que separaba los dominios públicos y privados sobre las aguas. Hasta antes de 1967, las aguas de dominio privado podían ser arrendadas o enajenadas, lo que con el paso de los años generó una enorme concentración de ese recurso, junto con afectar el riego del suelo agrícola. Con la nueva legislación de reforma agraria era el Estado el que podía facilitar derechos de aprovechamiento, sin que eso significara que el propietario de un predio se transformara, al mismo tiempo, en propietario de las aguas que escurrían en su interior.

En cuanto a los beneficiarios, la nueva normativa privilegió principalmente a la población de origen campesina. Esto representaba un importante cambio tomando en cuenta que la anterior Ley 15.020, aprobada bajo 
el gobierno de Alessandri, incluía también a técnicos y profesionales vinculados a la actividad agrícola. Sin embargo, la Ley 16.640 se centró, principalmente, en aquellas categorías laborales que se desempeñaban de manera estable en las grandes haciendas: inquilinos, medieros y asalariados permanentes. De manera que quedaban excluidos de los beneficios los trabajadores ocasionales, como los peones, y pequeños campesinos minifundistas, que no establecían ninguna relación de dependencia con la gran propiedad.

Contrario a lo esperado, las expropiaciones se fueron dando de manera lenta debido, en parte, a la presión que ejercían los terratenientes y a los resquicios legales que se podían apelar por parte de los propietarios afectados. Pero también influyeron las tensiones que surgieron al interior del propio gobierno. Al final del gobierno de Frei Montalva se había beneficiado solo al $20 \%$ de las familias que se contemplaba integrarían el área reformada (Barraclough y Fernández, 1974; Cereceda y Dahse, 1980; Huerta, 1989). Para revertir las dificultades que generaban determinados procedimientos legales, el senador del PDC presentó un proyecto complementario a la Ley 16.640 con el propósito de agilizar las expropiaciones y la toma de posesión por parte de la CORA, la Ley 17.280, que entró en vigencia en enero de 1970, y que fue promovida por el senador Aylwin, hizo más expedito los procesos de expropiación. Autorizaba a los funcionarios de la CORA a tomar posesión inmediata de los predios cuando éstos cumplían las condiciones para ser expropiados. De igual modo, la mencionada normativa autorizaba la expropiación de aquellos predios que eran objeto de "tomas" u ocupaciones por parte de sus trabajadores.

Tras la finalización del gobierno de Frei Montalva y el inicio del gobierno de la UP, presidido por Salvador Allende (1970-1973), la reforma agraria entró en una fase de profundización, al punto que a fines de 1972,el latifundio prácticamente había desaparecido de las zonas de riego de los valles central y sur. El ritmo de las expropiaciones se tornó mucho más acelerado, alcanzando rápidamente la suma de beneficiarios y de superficies incluidas al sector reformado, logradas hacia fines del gobierno anterior (Cereceda y Dahse, 1980; Huerta, 1989). Ahora bien, lo sobresaliente de la profundización de la reforma agraria bajo el gobierno de la UP, radicó en el hecho de que ella fue asumida en base a las instituciones que habían sido creadas en 1962, como la CORA y el INDAP, y a todos los aspectos legales que fueron aprobados durante el gobierno de Frei Montalva. No fue realizada otra reforma constitucional ni modificada la Ley 16.640, aprobada en 1967, así como tampoco las normas introducidas por el senador Aylwin a inicios de 1970.

La principal innovación del gobierno de Allende, se expresó mediante la creación de los Centros de Reforma Agraria (CERAS) y los Centros de Producción (CEPROS). Cabe destacar que los CERAS y los CEPROS no fueron establecidos legalmente, sino que, más bien, fueron concebidos en términos estrictamente administrativos. Los CERAS funcionaban de manera análoga a los asentamientos. Consistían en formas de propiedad colectiva, de carácter transitoria, que agrupaban a varios predios colindantes que 
habían sido expropiados. Los CEPROS, por su parte, funcionaban bajo la modalidad de fincas estatales. Normalmente eran empresas y predios dedicados a la producción agroindustrial, controlados por el Estado, con la finalidad de estimular un desarrollo estrictamente capitalista del agro. En su interior se desempeñaban técnicos y profesionales, además detrabajadores agrícolas asalariados.

\section{La participación campesina y su significado}

Hasta antes de 1964, la sindicalización campesina había sido bastante débil. La principal causa de esa debilidad se atribuye a las restricciones que imponía la Ley 8.811, aprobada por el gobierno de González Videla en 1947, y que se mantuvo vigente hasta antes de la aprobación de la Ley 16.625, aprobada pocos meses antes de que el Congreso Nacional hiciera lo mismo con la Ley 16.640. Con posterioridad a las reformas de 1958, y pese a la vigencia de la Ley 8.811, la izquierda, representada por el PC y el PS, así como el PDC se volcaron hacia las localidades rurales con la finalidad de atraer el voto campesino (Affonso et al, 1970; Loveman, 1976). Esos partidos, en especial el PC y el PDC realizaron una activa labor en las zonas rurales, cuya finalidad era, principalmente, impulsar la creación de sindicatos y federaciones campesinas. Ambos partidos crearon una suerte de plataforma que resultó fundamental luego de la aprobación de la Ley de Sindicalización Campesina, en abril de 1967. Principalmente la labor desempeñada previamente sirvió para la creación de nuevos sindicatos y la conformación de confederaciones que tuvieron presencia a nivel nacional.

Durante el gobierno de Frei Montalva, la organización de los trabajadores agrícolas y de los campesinos en general fue concebida como parte de su política de “promoción popular” (Huerta, 1989). Es decir, existía una clara intención por integrar a un sector históricamente excluido. Asimismo, el proceso de reforma agraria requería de un apoyo social significativo, debido a las eventuales reacciones contrarias que manifestarían las organizaciones de los terratenientes. El INDAP, como ya se ha descrito, durante los primeros años de ese gobierno, realizó una activa labor destinada a organizar a los campesinos, por medio de la creación de sindicatos. Con la aprobación de la Ley 16.625 se produjo un crecimiento cuasi exponencial del número de sindicatos controlados por el PDC, debido a que ese partido era el que al mismo tiempo controlaba los recursos del Estado. El predominio del PDC en el movimiento campesino se invierte, a favor de los sindicatos de la Confederación Ranquil,que habían sido creados por el PC y el PS (Loveman, 1976; Bruna, 1985). Tal situación demuestra la dependencia que se produjo entre las organizaciones campesinas y los partidos, y sobre todo cuando estos lograban el control de aquellos recursos que se podían ser movilizados desde el Estado.

En términos de las demandas y los conflictos colectivos, en los años de duración del gobierno de Frei Montalva el movimiento campesino se movilizó principalmente por reivindicaciones salariales (Affonsoet al, 1970). La demanda por la tierra fue notablemente escasa. Sin embargo, la situación 
comienza a variar hacia 1970, debido al problema de la lentitud de las expropiaciones registradas hasta ese entonces. A partir de ese año, la demanda por la tierra se convierte en la más importante, coincidiendo con la incorporación, como parte del movimiento campesino, de organizaciones mapuches. Empero, el fenómeno de la ocupación y de "toma” de tierras no solo sirvió para acelerar las expropiaciones, o reclamar por mejores condiciones salariales, sino también para actuar en contra del proceso de reforma agraria (Bengoa, 2015; Avendaño, 2017). Este tipo de ocupaciones se tornó en un instrumento efectivo que utilizaron los terratenientes, que instigaban a sus trabajadores a ocupar el predio antes de la expropiación, o a retomar uno ya ocupado.

Durante el gobierno de la UP, se fomentó la participación directa de los campesinos, en sus respectivas comunas, y un trabajo mancomunado con el Ministerio de Agricultura. Para tal finalidad se crearon los Consejos Comunales Campesinos, concebidos como "órganos de planificación, ejecución y control de la política agraria” (Maffei y Marchetti, 1971, p. 128; Gómez y Klein, 1972). La mayoría de los Consejos que lograron funcionar se crearon, a través de decretos, por los funcionarios de los organismos que asesoraban de manera directa al sector reformado. A nivel nacional, solo dos Consejos fueron creados por las bases del movimiento campesino en sus respectivos territorios (Bruna, 1985). En cuanto a las situaciones de conflicto, habría que destacar la presión que se ejerció hacia el gobierno para incorporar a quienes quedaban excluidos de la reforma. Normalmente esta presión provenía de organizaciones vinculadas a partidos de izquierda, sobre todo al "polo revolucionario" constituido en esos años. Será precisamente este sector que comenzará a plantear la necesidad de reducir el límite para las expropiaciones de 80 a $40 \mathrm{HRB}$. La otra fuente de conflicto provenía de la oposición, principalmente de las organizaciones campesinas vinculadas al PDC, que comenzaron a poner en cuestión el excesivo burocratismo que primaba al interior de los CERAS y de los CEPROS.

En consecuencia, el movimiento campesino chileno se constituyó por obra de los partidos y de las instituciones del Estado, como el INDAP, encargada de asesorar, formar dirigentes y promover la organización de ese sector. No fue posible el desarrollo de un movimiento autónomo del Estado, ni que antes de la reforma agraria fuera capaz de desafiar el poder hacendal, o bien desplegar acciones que permitieran revertir las limitaciones de aquella legislación aprobada en 1947. Tal situación va a marcar una diferencia sustantiva en comparación con la trayectoria y el desarrollo del movimiento campesino peruano.

\section{La reforma agraria en Perú bajo los militares}

Velasco Alvarado llega al poder tras un golpe de Estado que pone fin al gobierno de Belaúnde. La intervención de los militares seguía la línea del golpe llevado a cabo en 1962, que había expandido los órganos del Estado y erosionado la estructura de poder tradicional (Pease y Romero, 2013, p. 
231). En tal sentido, el golpe encabezado por Velasco Alvarado puso final al Estado oligárquico, el cual fue desplazado por una forma de Estado intervencionista. Se introdujeron importantes cambios en la propiedad que permitieron llevar a cabo la reforma agraria, expropiar empresas extranjeras y el control de los yacimientos petroleros por parte del Estado. Paralelo a esas medidas, el gobierno de Velasco Alvarado decidió excluir a los principales segmentos de la oligarquía peruana: los empresarios exportadores de azúcar, los terratenientes tradicionales y quienes controlaban el sistema financiero.

\section{Modernización económica y medidas antioligárquicas}

Durante el gobierno de Velasco Alvarado, la reforma agraria fue asumida como una medida de desarrollo que permitiría un crecimiento íntegro de la economía nacional. Asimismo, fue concebida como un proyecto antioligárquico que pretendía desplazar al sector social que controlaba y mantenía grandes propiedades sustentadas en relaciones laborales y de poder tradicional, como ocurría con aquellas que se encontraban en manos de los gamonales de la sierra. Ese fue el propósito subyacente en aquella ley aprobada el 29 de junio de 1969. Según explicaba el general Velasco Alvarado:

"la ley (de Reforma Agraria) se orienta a la cancelación de los sistemas de latifundio y minifundio en el agro peruano, planteando su sustitución por un régimen justo de tenencia de la tierra que haga posible la difusión de la pequeña y mediana propiedad en todo el país” (Velasco Alvarado [1973] 2014, p. 12).

Adicionalmente, agregaba que dicha reforma debía ser aplicada en todo el país, "sin reconocer privilegios ni casos de excepción que favorezcan a determinados grupos de interés" (Ibíd.). Aparte del desplazamiento del latifundio y del minifundio, la reforma contemplaba la formación de cooperativas para el manejo y el funcionamiento de las empresas agroindustriales.

Desde el punto de vista económico, el propósito de la reforma agraria estuvo focalizado en mejorar las condiciones para aumentar la producción agrícola. Hasta antes de la reforma agraria, la agricultura integraba alrededor del $40 \%$ de la población activa en el Perú. Pese a que la exportación de productos agrícolas había sido una importante fuente de divisas, la agricultura había ido perdiendo relevancia en favor de la minería, la actividad pesquera y las "exportaciones no tradicionales" (Caballero, 1980, p. 19). Se fue registrando una progresiva caída del aporte realizado por el sector agrícola al Producto Interno Bruto (PIB), sobre todo en los años previos a la implementación de la reforma agraria. En 1960, la agricultura constituyó el 20,3\% del PBI total, mientras que representó el 49,7\% de la Población Económicamente Activa (PEA); en 1975, transcurrida buena parte de la reforma agraria, el PEA rural llegó a representar el 41,8\% del total, aunque en su aporte al PIB total se había registrado una disminución al 
12,7\% (Schirner, 1977, p. 801).

La aspiración de debilitar a la oligarquía peruana se expresó de manera clara con la medida adoptada en relación a la mayor organización que agrupaba a los grandes terratenientes: la Sociedad Nacional Agraria (SNA). Seis días después de asumido el poder, el gobierno decidió efectuar una ocupación militar de los campos petroleros de Talara, e intervenir la IPC, filial de la StantarOil of New Yersy. De la misma forma, por medio de un amplio despliegue militar, el gobierno intervino las instalaciones azucareras ubicadas en la costa. Todas estas medidas tenían por finalidad asegurar el respaldo de los sectores populares, pese a que, en el caso particular de la intervención de las haciendas cañeras y algodoneras ubicadas en la costa, se pretendía, a su vez, desarticular las organizaciones campesinas controladas por el APRA y otras agrupaciones de izquierda (Valderrama, 1976, p. 420).

Por otra parte, al igual que en el caso chileno, la reforma agraria peruana contempló asegurar la propiedad de las aguas por parte del Estado y el control del manejo de ese recurso. Las autoridades decidieron desconocer los "derechos adquiridos" por parte de los hacendados de la costa, ya que se había generado una concentración del recurso hídrico en manos de los grandes terratenientes. Para esto se procedió a dictar un nuevo Código de Aguas, que reemplazaba una antigua legislación que se remontaba a principios del siglo XX. Esta y otras medidas adoptadas desde que se promulga la reforma agraria, en junio de 1969, llevaron al Estado a asumir una importante conducción y planificación de las transformaciones impulsadas. Por ende, fue necesaria la creación de una serie de organismos e instituciones destinadas a planificar y dirigir la actividad económica, junto a la integración y el fomento de la participación campesina.

\section{Aplicación de la reforma agraria}

El gobierno asumió desde un comienzo que la reforma agraria se implementaba en un país de una notoria complejidad geográfica y social. La Ley de Reforma Agraria establecía un impedimento para evitar la concentración de la propiedad rural y la del poder económico que de ella derivara. Al igual que en Chile, se planteaba que la tierra debía ser "para quien la trabaja”. Se establecía una sanción, que implicaba la pérdida de la propiedad, para quien hiciera mal uso, o desuso, de la tierra y de las relaciones laborales de servidumbre (Cf. Pease y Romero, 2013, p. 253). La Ley fijó como límite de extensión las 150 hectáreas para la zona costera, la que luego fue reducida a las 50 hectáreas.

En la sierra, los límites fueron establecidos distinguiendo entre tierras para cultivo y para pastos naturales. Los límites de las tierras de cultivo fueron fijados a 55 hectáreas, y entre 2.500 a 5.000 -según el grado de utilización en ganadería- para las de pastos naturales. Finalmente, dicha legislación aseguraba mantener el derecho de propiedad en aquellas unidades que se hubiesen visto limitadas por la reforma. 
Una de las primeras decisiones adoptadas por el gobierno de Velasco Alvarado fue anular el régimen de excepción para los complejos azucareros. Con ello las autoridades demostraban que no buscaban solo transformar las grandes propiedades que eran explotadas de manera ineficiente, sino se intentaba racionalizar, de forma planificada, los recursos de las empresas más productivas. Cabe señalar que antes de la reforma agraria los dueños de complejos azucareros, así como de las plantaciones algodoneras de la costa, exportaban de manera directa.

El gobierno fomentó la creación de empresas asociativas manteniendo el esquema empresarial de las haciendas costeras. De ese modo, se esperaba pudieran reorientar la utilización del excedente en función de la ampliación del mercado interno. Además, se ofreció la alternativa que los dueños de las grandes haciendas realizaran parcelaciones por iniciativa privada. En muchos casos, las parcelaciones se transformaron en una forma de precaución para evitar la expropiación de los predios, subdividiendo las propiedades entre los empresarios. A raíz de esta situación, el gobierno se vio obligado a suspender las parcelaciones, medida que fue adoptada, además, como respuesta a la movilización de los trabajadores costeños. Frente a esa movilización, el gobierno decidió a profundizar la reforma agraria y conceder a los campesinos "participación en las utilidades de las empresas agrícolas no reformadas" (Valderrama, 1976, p. 28).

Para la aplicación de la reforma, el gobierno tuvo que modificar parte importante de la estructura institucional. La Dirección General de Reforma Agraria, dependiente del Ministerio de Agricultura, fue el organismo encargado de la ejecución del proceso de reforma. Por medio de ese organismo, el gobierno se reservaba la facultad de determinar la modalidad y la calificación de los beneficios de la reforma, así como de la organización de las nuevas unidades productivas y territoriales derivadas de la expropiación de las haciendas. Como se ha indicado, el gobierno orientó parte importante de sus acciones a intervenir las empresas agrícolas ubicadas en la costa, con la finalidad de debilitar, en términos políticos y económicos, a la oligarquía peruana. Por otra parte, dispuesto a resolver los problemas de comunicación con los sectores populares, específicamente con los campesinos, el gobierno decidió crear el Sistema Nacional de apoyo a la Movilización Social (SINAMOS). El gobierno partía del supuesto que los sectores populares, en general, no se encontraban suficiente y debidamente organizados.

Sin duda, la particularidad de la reforma agraria peruana se reconoce en el carácter cooperativista y asociativo de ella, como consecuencia de la política impulsada por el gobierno. En relación a la agricultura fueron creadas las Cooperativas Agrarias de Producción (CAPs) y la Sociedad Agrícola de Interés Social (SAIS). Se trataba de dos empresas asociativas que asumieron un importante rol productivo. De ellas salía el $99 \%$ de la producción de azúcar y cerca del 40\% de la de algodón. Además, de ellas derivaba el 23\% de la producción de vacunos y el 23\% 
correspondiente a la de ovinos (García-Sayán, 1979, pp. 31-33). De ambas entidades, las CAPs eran las que tenían más importancia debido a que fueron ellas las que lograron cumplir las metas propuestas al inicio del proceso reformista (Matos Mar y Mejía, 1980, p. 90). Las CAPs consistían en unidades productivas indivisibles de explotación, cuyos bienes pasaban a ser de propiedad colectiva de quienes habían conformado la fuerza de trabajo de las empresas agrícolas reformadas. Constituidas las CAPs esos trabajadores participaban de la gestión y de los beneficios obtenidos. Las CAPs lograron promover un modo de organización de la producción y un estilo de gestión que sobresalió por sus niveles de eficiencia y de aumento de la producción. De hecho, hacia 1975 la producción de azúcar derivada de las CAPS se transformó en la principal fuente de divisas, dado que se llegaron a obtener alrededor 265 millones de dólares, 70\% de lo obtenido el año 1974 (Schirner, 1977, p. 817).

Las CAPs fueron también como instrumentos de cambio por el hecho de que tenderían a fomentar un sistema de autogestión entre los trabajadores que las integraban. Sin embargo, ni las CAPs ni tampoco otras entidades y formas asociativas que fueron creadas en el período de la reforma agraria se lograron transformar en formas de producción alternativas. Por el contrario, todas ellas tendieron a incrementar y consolidar un capitalismo agrario, contando además con un alto grado de intervención estatal (Valderrama, 1976, p. 30; Schirner, 1977, p. 828; Sulmont, 1978, p. 702). Pese al aumento de la producción, al interior de las CAPs se dieron otro tipo de situaciones, como las diferencias entre quienes se incorporaban a ellas como trabajadores respecto a la condición social de quienes no lograban ser incorporados. Tales diferencias se reconocían en términos de ingreso y en las posibilidades de consumo, notoriamente superiores entre los trabajadores que integraban las CAPs. Incluso, al interior de ellas fue posible constatar actitudes rechazo, por parte de quienes estaban integrados, ante la posibilidad de incorporar a trabajadores excluidos.

El desarrollo del capitalismo agrario generaba el control ejercido por los organismos del Estado trajo también consecuencias en las comunidades indígenas, que fueron obligadas a adoptar un estilo de gestión empresarial (García-Sayán, 1979, p. 33; Chonchol, 1994, p. 306). Las comunidades indígenas, que habían logrado mantener su autonomía e independencia organizativa frente al poder central, pasaban a ser objeto de normas específicas definidas por el gobierno ${ }^{2}$. La más importante de todas fue la promulgación del Estatuto Especial de Comunidades Campesinas (D.S. 37-70-A), de 1970, que puso fin a decenios de vida comunal obligando la constitución de cooperativas. Estas cooperativas incluían también a los pequeños propietarios independientes que se agruparon en torno a las Cooperativas Agrarias de Servicio (CAS) y en Cooperativas Agrarias de Integración Parcelaria (CAIP).

A partir de 1972, se toma la decisión desde el gobierno de dejar 
seguir expropiando haciendas de manera dispersa. Se definen acciones que se concentran en áreas específicas denominados Proyectos Integrales de Asentamiento Rural (PIAR). A su vez, se organizan los Proyectos Integrales de Desarrollo (PID), con el fin de hacerse cargo de la planificación y redistribución. Con estos organismos se pretendía consolidar la forma de gestión propuesta por el Estado en gran parte de la economía agraria.

\section{La participación campesina}

A diferencia del caso chileno, en donde el movimiento campesino adquiere fuerza y un notorio protagonismo político recién con la reforma agraria, en Perú se venía dando una activa participación que se remontaban a las primeras décadas del siglo XX, especialmente por parte de los trabajadores que se desempeñaban en las plantaciones de la costa (Valderrama, 1985, p. 128-129). Para el desarrollo del movimiento campesino peruano, fundamental resultó ser el vínculo establecido con el APRA, que fue capaz de desplegar acciones mucho más efectivas entre los trabajadores agrícolas, a diferencia del Partido Comunista (PCP) y Socialista Peruano (PSP). En los años cincuenta, el movimiento campesino peruano demostró una enorme capacidad de presión, por parte de campesinos sin tierra y que se oponían a la persistencia del orden hacendal. Pero el más exitoso de los movimientos campesinos en Perú se produjo entre 1962 y 1965, en la zona del valle de la Convención y de Lares. Poco antes se habían desencadenado huelgas de los trabajadores de las haciendas algodoneras y azucareras, junto a un activo movimiento de campesinos e indígenas cuya finalidad era la recuperación de tierras. Esta ola de movilizaciones logró "remecer al Estado, creando temor en los terratenientes” (Matos Mar, 1984, p. 33).

Desde que se da inicio a la reforma agraria, en 1969, los campesinos jugaron un rol activo, primero, al respaldar el proyecto y, luego, al demandar su profundización. Incluso, se movilizaron para evitar la subdivisión de las grandes haciendas por parte de sus propietarios. Sin embargo, el movimiento campesino va a reaccionar en contra del rígido verticalismo que imponía el gobierno de Velasco Alvarado al implementar el sistema de cooperativas. De todos modos, el gobierno va a desplegar una serie de iniciativas para canalizar todo el descontento con la política de cooptación que desarrolló, desde 1971, al crear el Sistema Nacional de Apoyo a la Movilización Social (SINAMOS). Por medio de la promulgación del decreto 19.400, el gobierno dio origen a una "central única campesina”, conocida como la Confederación Nacional Agraria, que estuvo bajo la dirección de SINAMOS.

El intento de cooptar políticamente a los campesinos, por medio de una central única controlada por SINAMOS, va a concitar una aguda resistencia de parte de sus organizaciones. Prueba de ello fue que el 
gobierno se vio enfrentado a la reorganización de la Confederación Campesina del Perú (CPP), la que mantuvo su autonomía respecto al régimen militar. La CPP se opuso a los requerimientos estatales desde el pago de la deuda agraria, la velocidad de las afectaciones de los terratenientes y el precio de los productos agrícolas (Cotler, 1991, p. 422). Su accionar llegó, incluso, a provocar un proceso de radicalización que se extendió a la misma Confederación Nacional Agraria (Valderrama, 1985, p. 143).

La exclusión de una gran cantidad de campesinos del proceso de reforma, junto al mantenimiento de formas productivas precapitalistas, que en algunos casos fueron adoptadas en las nuevas empresas asociativas, y el rechazo de parte de los campesinos a convertirse en asalariados de las empresas dirigidas por el Estado, generaron una serie de conflictos y oleadas de movilizaciones. De acuerdo a datos proporcionados por Denis Sulmont, en 1972 los sindicatos reconocidos y las huelgas del sector agrario representaban el 15\% y el 30\% respectivamente del total correspondiente a nivel nacional (Sulmont, 1978, p. 692).

Desde 1974, se registra un descenso de la movilización de los trabajadores costeños, trasladándose el conflicto hacia la sierra y a la región andina. Los efectos de la aplicación de las reformas agrarias mostraron una serie de situaciones contradictorias. En efecto, la masa de trabajadores de las antiguas haciendas, marginados del proceso de reforma, llevaron a cabo una serie de acciones, entre ellas la ocupación de 60 predios ubicados en la sierra que no habían sido afectados por la reforma agraria (Valderrama, 1976, p. 33; Valderrama, 1985, p. 43). En esas ocupaciones llegaron a participar alrededor de 20 mil campesinos, provocando con ello una fuerte represión de parte del gobierno.

\section{Conclusiones: Semejanzas y diferencias cruciales}

Varias son las diferencias entre los dos casos que hemos destacado a lo largo de este artículo. Estas diferencias impiden ser reconocidas como condiciones necesarias del resultado positivo que tuvo la reforma agraria en ambos países. Como lo ha venido planteando la literatura especializad en método comparado, la ausencia de un fenómeno en un caso y la presencia en otro se descartan como factores para entender un resultado similar, salvo cuando dicho resultado pasa a ser diferente. El debilitamiento del movimiento campesino, en la fase previa en Chile, y el desarrollo del mismo en Perú, no incidirían en el resultado del proceso de reforma agraria. Tampoco incidiría el hecho de que el régimen político haya experimentado variaciones entre ambos países: democrático en Chile y autoritario en Perú. 


\section{Tabla 2}

\section{Comparación entre las dos experiencias de reforma agraria}

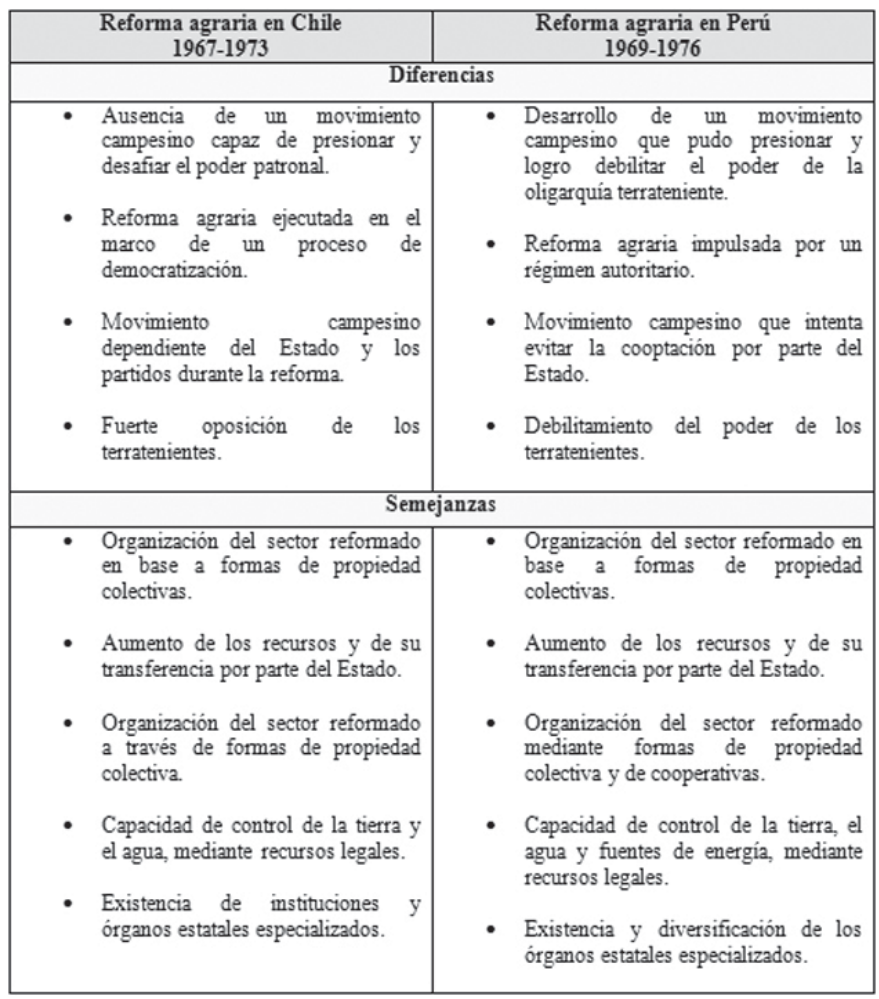

Fuente: Elaboración propia.

Por el contrario, se puede asumir que las similitudes que se producen en ambos casos durante la implementación de la reforma agraria podrían ser los factores decisivos. De los aspectos coincidentes habría que señalar, en primer término, lo clave que fue organizar al sector reformado mediante formas de propiedad colectiva, sean estos asentamientos, CERAS y CEPROS, en la experiencia chilena, o bien CAPs y SAIS en Perú. En segundo término, la racionalización de los recursos, debido a la organización del sector reformado del modo anteriormente señalado. En tercer lugar, el manejo de la tierra y del agua por parte del Estado. Esto último, en el caso chileno, fue clave para revertir los problemas de concentración del recurso hídrico, en los grandes terratenientes, y la disminución que anteriormente registraban las superficies de riego. Por último, habría que mencionar la presencia de instituciones y órganos estatales especializados. Algunos de ellos especia- 
lizados en el fomento productivo, otros en el trabajo con las organizaciones campesinas, o bien en la planificación y control de los recursos. Todo ello explicaría la razón por la cual se modificó la estructura de propiedad en ambos países y, en el caso chileno, por qué después de la reforma agraria no fue posible retornar a la situación anterior. 
Polis, Revista Latinoamericana, $N^{\circ}$ 47, 2017

\section{Notas}

${ }^{1}$ Este artículo ha sido elaborado en el marco del proyecto Fondecyt regular 1140639.

${ }^{2}$ Según recuerda Matos Mar, a partir de las primeras décadas del siglo XX los campesinos indígenas venían siendo "sometidos a la ley del hacendado o al apacible mundo andino de las comunidades libres y, desde entonces, reconocidas. Representaban más de las tres cuartas partes de la población peruana, pero no tenían ni voz ni voto en las instancias del Estado” (Matos Mar, 1984, p. 26-27). 


\section{Bibliografía}

Affonso, A.,Gómez, S., Klein, E., y Ramírez, P. (1970). Movimiento campesino chileno. Vol. I. Santiago, Chile: ICIRA.

Albertus, M. (2015). Autocracy and Redistribution. The Politics of Land Reform. Cambridge, EstadosUnidos: Cambridge University Press.

Avendaño, O. (2017). Los partidos frente a la cuestión agraria en Chile, 1946-1973. Representación de intereses, gradualismo y cambio estructural. Santiago, Chile: Lom Ediciones.

Avendaño, O. (2016). La reforma agraria durante el gobierno del presidente Eduardo Frei Montalva: un cambio estructural y la incorporación del campesinado. En Huneeus, C y Couso, J. (eds.). Eduardo Frei Montalva: un gobierno reformista. A 50 años de la "Revolución en Libertad”(159-195).Santiago, Chile: Editorial Universitaria.

Barraclough, S. y Collarte, J. C. (1972). El hombre y la tierra en América Latina. Santiago, Chile: ICIRA-Editorial Universitaria.

Barraclough, S. y Fernández, J. A. (1974). Diagnóstico de la reforma agraria chilena. México D.F., México: Siglo XXI Editores.

Bengoa, J. (2015). Historia rural de Chile central. Tomo II. Crisis y ruptura del poder hacendal. Santiago, Chile: Lom Ediciones.

Bruna, S. (1985). Chile: las luchas campesinas en el siglo XX. En P. González Casanova, (coord.). Historia política de los campesinos latinoamericanos(pp. 84-148). México D.F., México: Siglo XXI Editores.

Caballero, J. M. (1980). Agricultura, reforma agraria y pobreza campesina. Lima, Perú: Instituto de Estudios Peruanos.

Cereceda, L. y F.Dahse (1980). Dos décadas de cambio en el agro chileno. Santiago, Chile: Instituto de Sociología, Pontificia Universidad Católica.

Cotler, J. (1991). Perú: Estado oligárquico y reformismo militar. En P. González Casanova (coord.). América Latina: Historia de medio siglo(pp. 379-430). México, D.F., México: Siglo XXI editores.

Echenique, J (1972). Las expropiaciones y la organización de los asentamientos en el período 1965-70. En D. Alaluf, S. Barraclough, A. Mattellard, P. Sampaio y A. Corvalán, J. Echenique. Reforma Agraria chilena: Seis ensayos de interpretación(pp. 93-110). Santiago, Chile: ICIRA. 
Polis, Revista Latinoamericana, $N^{\circ}$ 47, 2017

Fajardo, J. C. (2009). Organización y participación política en el Perú, antes y durante el gobierno de Juan Velasco Alvarado. Lima, Perú: Editorial Universitaria.

García, A. Reforma Agraria y economía empresarial en América Latina. Santiago, Chile:Editorial Universitaria, 1967.

Gómez, S. (2015). El caso de Chile. En G. Almeyra, L. Concheiro, J. Mendes y C. Porto-Goncalves. Capitalismo, tierra y poder en América Latina (pp. 135-169). Buenos Aires, Argentina: Continente.

Gómez, S. (1986). Tenencia de la tierra, Chile 1965-1985. Documento de Trabajo $\mathrm{N}^{\circ}$ 286. Santiago, Chile: FLACSO.

Gómez, S. y Klein, E. (1972). Informe sobre el estado actual de los Consejos Comunales Campesinos. Santiago, Chile: ICIRA.

Huerta, M. A. (1989). Otro agro para Chile. La historia de la Reforma Agraria en el proceso social y político. Santiago, Chile: CISECCESOC.

Kaufman R. (1972). The Politics of Land Reform in Chile. 1950-1970. Public Policy, Political Institutions, and Social Change. Massachusetts, Estados Unidos: Harvard UniversityPress.

Kay, C. (1986). Hacia una teoría del cambio agrario en Chile. Santiago, Chile: GEA.

Kay, C. y Pineda, M. (1998). ¿El fin de la reforma agraria en América Latina? El legado de la reforma agraria y el asunto no resuelto de la tierra. Revista Mexicana de Sociología. 60 (4), 63-98.

Kurtz, M. J. (2004). Free Market Democracy and the Chilean and Mexican Countryside. Cambridge, EstadosUnidos: Cambridge University Press.

Lapp, N. (2004). Landing Representation and Land Reform in Latin America Votes. Nueva York, EstadosUnidos: Palgrave MacMillan.

Loveman, B. (1976). Struggle in the Countryside. Politics and Rural Labor in Chile, 1919-1973. Bloomington, Estados Unidos: Indiana UniversityPress.

Matos Mar, J. (1976). Yanaconaje y reforma agraria en el Perú. Lima, Perú: Instituto de Estudios peruanos.

Matos Mar, J. (1984). Desborde popular y crisis del Estado. El nuevo rostro del Perú en la década de 1980. Lima, Perú: Instituto de Estudios peruanos. 
Matos Mar, J. y Mejía,J. M. (1980). Reforma agraria: logros y proyecciones. Lima, Perú: Instituto de Estudios peruanos.

Mattelart, A. (1972). Apuntes sobre el concepto de reversibilidad de un proceso de reforma agraria. En D. Alaluf, S. Barraclough, A. Mattellard, P. Sampaio y A. Corvalán, J. Echenique. Reforma Agraria chilena: Seis ensayos de interpretación. pp. 69-92.Santiago, Chile: ICIRA

McCoy, T. L. (1969). The Politic of Structural Change in Latin America: The case of Agrarian Reform in Chile. WorkingPaper No 37. Ohio, Estados Unidos: Ohio StateUniversity.

Moreno, R. (2013). Sin reforma agraria no habría sido posible. Memorias de la Reforma Agraria chilena 1958-1970. Santiago, Chile: Ediciones Copygraph.

Morlino, L. (2005). Introduzione alla ricerca comparata. Bolonia, Italia: Il Mulino.

Pease G., H. y Romero,G. (2013). La política en el Perú del siglo XX. Lima, Perú: Fondo Editorial de la Pontificia Universidad Católica del Perú.

Pérez-Liñán, A. (2015). El método comparativo: fundamentos y desarrollos recientes. En R. Castiglioni y Fuentes, C (eds.). Política comparada sobre América Latina: teorías, métodos y tópicos (pp. 47-76). Santiago, Chile: Ediciones Universidad Diego Portales.

Ragin, Ch. (1989). The Comparative Method. Moving beyond Qualitative and Quantitative Strategies. Berkeley-California, Estados Unidos: University of California Press.

Rubio, D. (2013). Las guerrillas peruanas de 1965. En H. Pease G. y Romero, G. La política en el Perú del siglo XX (pp. 221-224). Lima, Perú: Fondo Editorial de la Pontificia Universidad Católica del Perú.

Schirner, U. (1977). Reforma agraria y cooperativismo en el Perú: Cambios estructurales y contradicciones de la nueva política agraria del gobierno militar del Perú. Revista Mexicana de Sociología. 39 (3), 799-856.

Seligmann, L. (1995). BetweenReform and Revolution. PoliticalStruggles in thePeruvian Andes. California, Estados Unidos: Stanford UniversityPress.

Sulmont, D. (1978). Conflictos laborales y movilización popular: Perú 1968-1976. Revista Mexicana de Sociología. 40 (2), 685-726.

Valderrama, M. (1976). Siete años de reforma agraria peruana, 19691976. Lima, Perú: Pontificia Universidad Católica del Perú. 
Polis, Revista Latinoamericana, $N^{\circ}$ 47, 2017

Valderrama, M. (1985). Historia política del movimiento campesino peruano en el siglo XX. En P. González Casanova (coord.). Historia política de los campesinos latinoamericanos (pp. 128-145). México D.F., México: Siglo XXI Editores.

Velasco, Juan ([1973] 2014). La revolución peruana. Buenos Aires, Argentina: EUDEBA.

Recibido: 09.06.17

Aceptado: 03.07.17 